\title{
A Common Heritage: EU Environmental Law and National Judges*
}

\author{
Julio Garcia Burgues ${ }^{1}$, Werner Heermann ${ }^{2}$, Yves \\ Kreins $^{3}$, Luc Lavrysen ${ }^{4}$, Frédéric Tiberghien ${ }^{5}$
}

\begin{abstract}
Enforcement of EU environmental law is one of the most prominent challenges in the field of environmental policy. In this respect, national judges have to play a key-role for ensuring that EU environmental law is correctly applied. They have to guarantee that protection of environment as provided by EU law is a reality for more than 500 millions citizens. The recent new initiatives of judges and the Commission for developing co-operation among judges in Europe are demonstrating that, more than before, national judges are open to compare and discuss practises in different Member States.
\end{abstract}

\section{Keywords}

Enforcement; Judges; EU law and national law

It is not possible to understand the success of EU environmental law if too little attention is paid to the specific mechanisms in place in the European Union which ensure the effective implementation of law. The EU legal system has proven to be extremely efficient for harmonization and creation of a common legal culture among Member States, in particular as regard environmental law: EU environmental law has become in a few decades the main source of inspiration for national environmental law in the EU Member States.

\footnotetext{
*) The views expressed in this article are personal and do not necessarily reflect the position of the European Commission.

1) Head of Unit, Directorate General Environment, European Commission.

2) Vice-President of the Association of European Administrative Judges.

3) Secretary-general of the Association of the Councils of State and Supreme Administrative Jurisdictions of the European Union.

4) President of the EU Forum of Judges for the Environment.

5) Rapporteur général, French Council of State.
} 
This paper explores recent trends in the development of co-operation between EU judges. It shows that development of EU environmental law is also changing traditional attitudes of national judges who move from attitudes centred on national issues towards more openness to cross-boarders co-operations.

\title{
I. Setting the Scene: The Need for More Co-operation between National Judges.
}

\section{I.I. National Judges and EU Environmental Law}

The application of EU environmental law by national courts is a daily task of judges. Indeed, as Gil Carlos Rodríguez Iglesias, former President of the European Court of Justice, wrote in his contribution to the Global Judges Symposium on Sustainable Development and the Role of Law (Johannesburg, 2002):

\begin{abstract}
All national judges — tens of thousands of them-are competent to apply EC law on an everyday basis. They apply it directly; they interpret their national laws in conformity with it, if at all possible; if not, they must leave aside national laws that are contrary to EC law, because it is the duty of national judges to guarantee the rights provided for in the Treaty and in EC legislation. In other words, individuals may rely upon the provisions of Community law before national courts without any implementing element of domestic law; the only requirement being that the provisions relied upon should be sufficiently clear and unconditional to create such rights. The co-operation between the Court of Justice and the national courts through the preliminary reference procedure has been decisive in ensuring the proper application of Community law and the protection of individual rights created by the Community legal order. The Court's jurisprudence in the area of environmental protection shows particularly well the important role that national judges play in the implementation and enforcement of obligations created by Community directives.
\end{abstract}

The role of the national courts in the application of EU environmental law is not more complicated than in the application of domestic law in the ideal situation where EU Directives are transposed timely and correctly into domestic law by legally binding rules in a way that is consistent with both the provisions of primary European law, taking into account the latest case law of the ECJ, and with other pieces of domestic law, and that the Member States have adopted the necessary complementary provisions to EU Regulations in time. However, such an ideal situation does not seem realistic. It is sufficient to look at the statistics of the European Commission's Environment DirectorateGeneral to realize that the transposition of European environmental law into 
domestic law is not a success story. According to the figures for 2007, with 479 files under investigation, DG Environment still has the highest number of open cases in the Commission. On average, $20 \%$ of Commission infringement actions are handled by the Environment Directorate-General. Also the high number of condemnations of Member States by the ECJ for bad application of EU environmental law shows that the situation is far from ideal. So the reality seems to be that in the vast majority of Member States one is confronted with relatively poor or delayed transposition of an important number of Environmental Directives and bad application of certain Environmental Regulations.

In such circumstances the role of the national judges in upholding European Environmental Law is crucial, but at the same time complicated. The judge has to look at his domestic law with a critical eye. He has to make an in-depth analysis of European Environmental Law, taking into account the ever growing body of case law of the ECJ. Has the rule of EU environmental law which is thought to be violated, direct effect or not? Is, according to the domestic legal order, such an effect necessary in order that a rule of European Environmental law can be invoked before the national judge, or can such rules be invoked always when they are relevant for the outcome of the case, even when they have no "direct effect"? Is the party who argues that the provisions of a Directive are violated, entitled to raise this argument, taking into account that Directives do not produce horizontal or third-party effect, but can produce on the other hand horizontal side-effects or direct vertical effect? If there are certain differences between domestic and $\mathrm{EU}$ environmental law the judge must ask if such differences are allowed by European law. He/she must look at the nature of the Directive. Does the Directive provide for minimum or uniform harmonization, or for a mixed or other form of harmonization? Where the Directive provides for minimum harmonization, does the domestic law comply with the minimum requirements of the Directive? If domestic law goes further than such a Directive, are those more far-reaching requirements compatible with primary European law? Where the Directive provides for uniform harmonization, is there nevertheless room for more far-reaching requirements, on the basis of secondary or primary European law? If differences between domestic and European law are not allowed by European law, can these differences be smoothed out by interpreting domestic law in such a way that it becomes consistent with European law? Can this be done within the boundaries set by the ECJ in its case-law? If consistent interpretation is not possible, to what extent must domestic law be set aside or annulled, should national law allow? In case of annulment, what should be its scope and should 
this operate with fully retroactive effect or not? Is there still room for balancing interests and to what extent? If there is a question of bad application of EU environmental law, can the Francovich doctrine on state liability for failed transposition be applied, and how should it be applied within the domestic procedural framework?

Different types of questions on the validity and interpretation of EU environmental law may thus arise before national judges. Judges may feel that in some situations it is necessary to refer such cases to the ECJ for a preliminary ruling and, should such a question arise before the highest national court, they may be obliged to refer the question. It seems however that the willingness to raise such questions varies considerably from one Member State to another. The ECJ delivered, in the period up to early 2008, I 02 judgments on preliminary questions referred in environmental matters (without taking into account "internal market" cases with an environmental dimension). Italian judges were the most active in referring such questions, with a total of 25, followed by the Netherlands with I8, France with I7, Belgium with I I, Germany and the UK with 9 each, Austria with 6, Denmark with 3, Finland with 2, and finally Luxembourg and Sweden with I each. This means also that from the EU I 5 , there were no such cases from Greece, Spain, Ireland and Portugal.

These figures cannot be interpreted as a sort of hit parade of Member States, starting with those Members States with the most problematic implementation status and ending with those where there are no such problems at all. It is sufficient to look at the pending infringement cases or those that have already been decided to discover that the record of Greece, Spain, Ireland and Portugal is far from brilliant in this respect. At the same time, however, we can also not say that the figures imply the opposite, because there is no clear match between these two statistics. Perhaps these figures can, with some caution, be interpreted as an indicator of the willingness of national judges to give precedence to European environmental law over domestic law. Some caution is indeed recommended. The better the implementation situation is, the less the need to consult the ECJ.

It may indeed be assumed that many cases are settled by national courts without it being necessary to refer questions to the European Court of Justice for a preliminary ruling, either because the court is of the opinion that there is no reasonable doubt about the validity or interpretation of the provisions of European law relied upon (the so-called "acte claire"), or because those questions could be solved on the basis of the existing case-law of the Court of Justice (so-called “acte éclairé”). 
Of course, this also means that there is an important need to train national judges in European law in general and in European environmental law in particular.

\section{I.2. Why do European Judges Have to Increase Co-operation?}

Based on the above description of the role of national judges as regard implementation of EU law, it is possible to sum-up the main reasons for the need of co-operation between national judges with the four following items:

- Firstly, EU law is today the main source in the development of Member States' national environmental law.

- Secondly, the national judges since they are in charge of the daily application of EU law are not only interested in knowing rapidly what is ruled at Union level but also what Courts in other Member States are deciding. In the long run, this is the only way to organize some convergence of solutions developed by national Courts in the European Union.

- Thirdly, most judges in charge of environmental cases are not specialists in this specific domain since they dedicate a limited amount of time to this category of case. These non-specialized judges request the information and training that will give them the key elements to allow them to access this matter, characterized by its technical and complex nature.

- Fourthly, the principle of mutual recognition of legal decisions being a corner-stone of the European Justice Area, implies that mutual confidence in equity and efficiency of legal proceedings is reinforced. As a consequence, this has an impact on reinforcing the competences and training of judges.

\section{The Emergence of a Common Culture among EU National Judges}

\section{I. Role of Existing Associations of Judges}

Recent years have seen the development of professional associations grouping national judges with an explicit objective of increasing the co-operation between national judges. The evolution from informal contacts between judges or national Courts to more structured co-operation is a clear sign of a change of scale in the objectives: European associations of Judges want to play a key-role in developing a European culture among judges. 
I. Association of the Councils of State and the Supreme Administrative Jurisdictions of the European Union

The Association of the Councils of State and the Supreme Administrative Jurisdictions of the European Union (ACA-Europe) is more than an association of judges. It regroups the administrative Supreme Courts of the 27 MemberStates of the European Union as well as the Court of Justice of the European Communities. The association plays a key-role in reinforcing communication between the members of the association on one hand and between Courts and European institutions on the other. It contributes to a permanent dialogue between judges and is a perfect platform for exchanges of case-law developed by Supreme Courts, in particular in the domain of environmental law. The association is essential for a better evaluation of the role of the national administrative judge in the implementation of Union law and as such, in the near future, it will play the role of ambassador of the Supreme Administrative Courts for the European Institutions more and more. Its domain of activity is much broader than European environmental law but this specific domain has taken on a specific importance, in particular in the jurisprudence of the Court of Justice. As a consequence, the association has recently organized several conferences on this topic. For instance, the Colloquium which took place in Leipzig in 2006 was dedicated to "National road planning and European environmental legislation-A case study-"-and the Seminar in Brussels in January 2008 was dedicated to "The administrative judge and EU environmental law".

\section{Association of European Administrative Judges}

The Association of European Administrative Judges (AEAJ) is an organisation founded in 2000. AEAJ is an apex-organization that consists of national associations charged with the representation of the interests of administrative judges. Apart from promoting common professional interests the association wants to contribute to a common judicial culture in Europe and endeavours to develop standards of good, or even, best practice. AEAJ pursues inter alia the target to help broaden the knowledge of legal redress in administrative matters among administrative judges in Europe, and to this purpose, to have an intense exchange of information on pertinent legislation and case law. In this context the eminent influence of European environmental law on the national legislation must be taken into account. The association has established different work groups, inter alia, a work group on Environmental Law, which was represented at the conference held in Paris. The role of this work group must 
not merely be limited to an exchange of experience among experts. This target can be combined with training judges, especially from new Member States in environmental law. The work group is open to a close cooperation with the Directorate Environment as a means to develop common and adequate environmental standards.

\section{Forum of EU Judges for the Environment}

With a view to enhancing the capabilities of national judges to tackle problems of inter alia European Environmental law, the EU Forum of Judges for the Environment (EUFJE) was established on 28 February 2004. It is an international non-profit association established under Belgian law. The objective of the Forum is to promote the enforcement of national, European and international environmental law in a perspective of sustainable development. The aim of the Forum is, in particular, to exchange experiences in the area of training of the judiciary in environmental law, contribute to a better knowledge of environmental law, share experiences of environmental case law and contribute to a more effective enforcement of environmental law. Every judge in the European Union and the European Free Trade Association with a special interest in environmental law can become a member of the Forum. Judges from countries that have applied for membership of the European Union may be admitted as observers. Representatives of the United Nations Environment Programme (UNEP), the European Commission and the Council of Europe may attend the meetings as observers. The initiative is in keeping with a worldwide initiative that was taken by the United Nations Environmental Programme (UNEP). During the annual conferences, which are supported by DG Environment of the European Commission, it is mostly European Environmental law that is to the forefront of the agenda.

\subsection{Current Dialogs among National Judges, Some Examples of Recent Develop- ments}

The role of the Court of Justice of the European Union is to ensure a harmonized - if not uniform - application of EU law, in particular EU environmental law. The preliminary ruling has a central role in this matter. However, it should be stressed that this mechanism works only on the initiative of national judges. They master the process. It is therefore of the greatest importance that these judges not only have enough knowledge of EU law but also that they know, in detail, the mechanisms available in their relationships with the Court 
of Justice, in particular, with regard to verifying national conformity with the rules developed at EU level.

This issue was one of the key-factors governing the development of the ACA-Europe. This leads to the development of concrete actions such as the development of the JURIFAST data base which today allows access, with the help of a search-engine, not only to preliminary rulings from the Court of Justice but also to decisions taken by national supreme Courts as a followup to these preliminary rulings as well as important decisions from national supreme Courts when no preliminary references have been done. The selection of decisions included in the database is left to Court in charge which should evaluate the interest to other Courts of the preliminary question and the answer given by the Court of Justice. In addition, the database DEC-NAT, which will be soon available via EUR-Lex, includes more than 20,000 references to national decisions related to EU law as well as to notes and commentaries related to these decisions. These tools are completed by a forum open to Supreme Court judges allowing judges confronted with difficult questions on the application of EU law to ask other judges in other EU Member States to share some similar experiences.

These tools are examples of the recent developments and intensification of European dialogue at two different levels: on the one hand between national judges and the European Court of Justice, on the other hand, between national judges. The need for these exchanges has led to the setting-up of a Working Group managed by the Dutch Council of State. This Working Group, known as "The Hague", recently delivered a report approved by the General Assembly of the ACA-Europe and the Network of the Presidents of the supreme judicial Courts of the E.U.. ${ }^{6}$ In the introduction of this Report, the Vice-President of the Dutch Council of State, Mr Tjeenk Willink, analyses, under the heading "What can National Courts do?", three priorities as follows:

As a first priority, the working group recommends raising the level of knowledge of European law of all judges. The Working Group regards this as a priority relevant to both the national courts and national institutions providing training, refresher courses and continued education courses. Adequate and accessible European law training for judges should be ensured at national level.

—As a second priority the Working Group recommends the immediate and full

6) This report was a working document for the symposium organized by the European Court of Justice in Luxembourg on 30 and 3I March 2009. Many Presidents of the Constitutional Courts, Supreme Courts, Council of States and Supreme Administrative Courts participated to this conference. 
publication of all preliminary references on a national and a European level as these contain important information for the judge who has to assess the need for filing a reference. This recommendation is addressed to all National courts and, especially, to the Supreme courts as well as to the Association, the Network and the Court of Justice. In this respect the working group proposes that the Association and the Network might cooperate for the benefit of the members of both organisations.

-As a third priority the Working Group recommends a number of "good practices" to the National courts which should expedite the handling of cases both on the national level as on the level of the Court of Justice.

Without minimizing the importance of the other two priorities, quite the reverse, I myself regard the first of these three priorities as the basic message of the working group. Here the working group points out the sore spot, especially as a recent survey showed that $60 \%$ of the national judges themselves in Europe take the view that they have an insufficient knowledge of European law.

It is absolutely essential that all national judges should raise their level of knowledge of European law as quickly as possible, in particular with a view to a better functioning of the preliminary rulings procedure.

The judges and their training institutes should put this matter first, the national States should provide the judge with the necessary means for that purpose.

In my view, it is the duty of the supreme courts of the countries of Europe, which form the Association and the Network, to promote the ideas and the proposals of the working group on this matter with governments, councils for the judiciary, establishments for training and continuing education of judges, and with lower courts, so that the European knowledge level of all judges should effectively be raised and that they should be able to fully carry out their tasks as co-actor of European law.

There is clearly interdependency between the level of knowledge of EU law, the access to preliminary references and good practise in its usage, and the training of national judges. The example of exchanges of practises in the domain of preliminary references shows how efficient best practices sharing can be. Judges are now more and more asking the questions: how other Courts have approached the problem I am facing? How does my national practice of EU law compare with the one developed in other Member States?

\subsection{The European Commission and the National Judge}

The communication from the Commission entitled "A Europe of resultsapplying Community law" $\operatorname{COM(2007)~} 502$ final and a specific Communication on E C environmental law $\operatorname{COM}(2008) 773$ adopted on I9 November 
2008 stressed at the political level the importance of the correct application of Union law and insisted on the role of the national courts and judges in this respect. In this context, the strengthening of cooperation between the national courts and the Commission departments is regarded as an essential step in improving the implementation of Union environmental law.

It is not necessary to recall that national judges, who deal with the ordinary jurisdiction of Union law, are more than ever guardians of the applicationat a level close to the citizen - of Union law that is increasingly present in national legal systems. Of course, the Commission has the power of referral to the Court of Justice, but in a geographical area comprising 27 Member States and nearly 500 million inhabitants, it is evident that the actions of the Commission can only regulate a minute part of the litigation relating to the application of Union law. Therefore, we must think in terms of partnership between the Commission and judges, while respecting the independence of judges.

This approach of the Commission which is paying more attention to national judges' role, meets the need expressed by judges to increase EU co-operation.

\section{The Way Forward: Objectives and Actions}

\section{I. Developing Dialog between EU National Judges in EU Environmental Law}

On 9-1o October 2008, a Conference took place in Paris on the role of the national judges in enforcement of EU environmental law. This event stems from a joined diagnosis between the European Commission and professional Associations of judges: common efforts for better implementation of EU environmental law have to take place. The Conference confirmed the interest of judges for more co-operations with EU institutions. It has demonstrated that judges in Europe are asking for more opportunities to exchange views and to benefit from experiences in different EU countries.

During the Conference, judges reviewed their needs in terms of information, training and co-operation. Information is necessary but today it is not the main problem: information is ensured through access to legal web-sites which are currently gathering case-law (ECJ, Commission, Judges' associations, lawyers' associations, and law journals). Three levels of training have to be distinguished: initial curriculum for judges which is the responsibility of Universities or Legal Schools; life-long learning during a judges' career; consultation and information for judges on new laws in order to better guarantee effective implementation 
Initial training is the main initiative to be addressed by Member States: they have to organize and include teaching of general principles of EU law and environmental law.

Based on this diagnosis, the Commission organised a co-operation program with national judges. Two seminars were held in 2009 (Bulgaria and Lithuania). This was followed by 4 seminars in 20 Io (France, United-Kingdom, Germany, Slovenia). The approach was to rely on training seminars for national judges and workshops between judges of different nationalities and the Commission in order to improve mutual knowledge of working methods. These first seminars dealt with EU nature law and EU waste law.

It should be stressed that the objective was not to develop a programme as if there were no existing national-level training courses intended for judges or as if this training did not take account of European law. The programme was hosted by national training centres and developed in close cooperation with them by the European Institute for Public Administration. The added-value of an action at Union level is indeed to encourage exchanges between the different Member States and legal traditions, as well as between the national courts and the Commission in order to improve a uniform implementation of Union law. The more than 100 judges from 20 Member States that participated in these meetings gave very positive evaluations. Further such seminars which will be organised in the coming years. ${ }^{7}$

\subsection{Some Lessons Learnt as Regard Obstacles to Uniform Implementation of EU} Environmental Law

Some lessons could already be drawn from the first workshops organized in 2009 and 2010. In all seminars, the role of procedural rules was the most important point highlighted by national judges. Facing cases-studies based on application of EU law, judges from different Member States may lead to different decisions not because of different interpretations of EU law but because of the impacts of procedural rules on their final decision.

If we had to draw a typology of procedural questions related to implementation of EU law, this would lead to these different categories:

- Firstly, access to justice questions. Given the diversity of legal systems and traditions within the EU Member States, access to environmental justice is not homogenous: legal standing, in particular in case of collective actions, is

\footnotetext{
7) For more information, http://ec.europa.eu/environment/legal/law/judges.htm.
} 
not evaluated in the same way although Member States-except Irelandand the EU are parties to the Århus Convention which is included in the acquis communautaire.

- Secondly, the level of control developed by judges varies from one country to another, depending on the terms used (person potentially affected by environmental damages, definition of waste), on the concepts used (gravity of damage or impact, major imperative public interest, appropriate evaluation of impacts of a project, project likely to have a significant effect on a site), on the techniques used for interpretation of legal texts, on the rules governing the burden of proof, on the recognition, or not, of the direct effect of international Treaties or of some elements of these Treaties, on the possibilities given to judges to control, in detail, the facts and legal norms used by authorities and to reform or include additional prescriptions in consents or permits delivered by authorities. In this context, the relationships between experts and judges, bearing in mind the role of scientific uncertainty and of the precautionary principle in EU environmental law, is considered to be a major domain for co-operation between judges. Since the full implementation of EU environmental law also requires the development of interim measures, it has been recognized that judges' competences and powers are among the most promising themes for discussion.

- Thirdly, the existence or not of effective remedies: in this respect the possibility to ask for interim measures or to suspend an act which is prima facie violating EU law is clearly a key-factor for guaranteeing effectiveness of EU law.

These elements are probably not a surprise for many lawyers. However, it is clear that correct implementation of EU law could not ignore that, beyond the necessary correct transposition of EU legal texts, there is a need to investigate how the legal systems make EU law effective. The first step in this likely long way for more harmonization in this area is probably that judges themselves identify differences between jurisdictional approaches.

This approach is clearly supported by the Vice-President of the French Council of State, Jean-Marc Sauvé:

Certain European Community directives dealing for instance with protecting the environment or contracting in the field of public works or public utilities do raise some germane and very difficult issues; it might then be interesting to share our experiences. As for implementing properly European law at the global level, I strongly advocate developing such new forms of cooperation between us. A common ambition we may share would be to set up the network of a European community of judges. What 
is at stake is of course not to determine which model is the best one, to export our domestic legal concepts, nor is it to give away our specific aspects or differences which are part of our legal and even cultural heritage. What we could achieve would be to open our eyes more widely to what is being done across our legal borders, and to improve our proceedings and concepts in the light of other proceedings and concepts already familiar to other systems. ${ }^{8}$

8) King's college (London), 27 november 2007, Lecture for the Lord Slynn of hadley European Law Foundation. 